\title{
Unresolved questions in nudging research: Putting the psychology back in nudging
}

\section{David R. Marchiori | Marieke A. Adriaanse | Denise T.D. De Ridder}

Department of Social, Health, and Organizational Psychology, Utrecht University, Utrecht, The Netherlands

\section{Correspondence}

David R. Marchiori, Department of Social, Health, and Organizational Psychology, Utrecht University, Heidelberglaan 1, P.O. Box 80140, 3508 TC Utrecht, The Netherlands.

Email: d.r.marchiori@uu.nl

\section{Funding information}

Netherlands Organization for Scientific Research (NWO), Grant/Award Number: FCBG 057-13-001.

\begin{abstract}
Nudging interventions are broadly defined as a rearrangement of a choice context that gently suggests a specific choice. Their increasing popularity has attracted attention and discussion from researchers, policy makers, and practitioners alike. After some applications to domains such as health, environmental issues, and retirement savings, the next step in nudging is to understand the psychological boundary conditions when applied to varied domains of daily life. It is yet unclear for example to what extent nudging interventions can be transparent without losing effectiveness, or how permanent the effects are. These unresolved questions may have contributed to heated political and scientific discussions, on for example the ethics of using nudges in the public health domain, due to the missing scientific evidence. Indeed, this popularity may have led to forget how nudging harnesses insights from decades of research in psychology to change people's behavior. The aim of this paper is to shift the focus back to the psychological premises nudges were built upon. It summarizes several outstanding questions that future research in the psychology of nudging should address. Advancing research in nudging will help to improve our understanding of applied nudging interventions and provide clarity to debates such as ethical appropriateness, effectiveness, and public approval.
\end{abstract}

\section{KEYWORDS}

disclosure, freedom of choice, future research, long-term consequences, nudging, policy debates, transparency

\section{1 | INTRODUCTION}

Nudging comprises a host of interventions that policy makers and others with responsibilities over a group of people can implement to help citizens to make responsible decisions (Thaler \& Sunstein, 2008). For example, to increase healthy food choices, healthy meal options can be placed on the first page of menus or at eye level in supermarkets and cafeterias (Prinsen, De Ridder, \& De Vet, 2013; Skov, Lourenço, Hansen, Mikkelsen, \& Schofield, 2013; Van Kleef, 
Otten, \& van Trijp, 2012). The original definition of nudging describes these interventions as physical changes in the choice architecture that influence people's choices in a predictable way, and do not forbid or make any option more costly in terms of time, money, trouble, or social sanctions (Thaler \& Sunstein, 2008). Several studies have shown that desired choices can be promoted without putting any limitations on the choice options that individuals have at their disposal. For example, in a recent study in a shop at a train station, researchers replaced the unhealthy snacks at a cash register with healthy products, while moving the unhealthy snacks at a different location in the store (Kroese, Marchiori, \& De Ridder, 2015). This intervention nearly doubled the sales of healthy food over a week, while keeping customers' freedom of choice intact. Past research has shown that nudging can be effective to tackle societal issues such as organ donation, obesity, retirement savings, divorce, and environmental issues (see Thaler \& Sunstein, 2008; Hollands et al., 2013; Whitehead, Jones, Howell, Lilley, \& Pykett, 2014). This burgeoning type of intervention has been embraced by researchers, policy makers, private companies, and practitioners alike. For example, researchers have been appointed to advise politicians about the use of nudges in countries such as the U.S.A., UK, Canada, Australia, France, Germany, Italy, the Netherlands, and Denmark (Blumenthal-Barby \& Burroughs, 2012; Whitehead et al., 2014). Considering that nudging is nowadays being used in new areas of policy making, we believe that the time has come to take another look at nudging, to identify open questions, and discuss how research in psychology can help shed light on some outstanding issues.

\section{1 | Origin of nudging}

The theoretical principles of nudges have been known for quite a while and are not new, in contrast to the implementation and use of these insights by policy makers to change people' behaviors. Nudging is based on findings from studies conducted in these last three decades in psychology. Researchers have shown that many human behaviors are guided by processes that operate outside of conscious awareness (see Bargh \& Chartrand, 1999; Hofmann, Friese, \& Strack, 2009; Kahneman, 2012; Smith \& DeCoster, 2000). Decisions are influenced by apparently trivial cues in the environment of which we are often not aware of, such as a smell, a melody, or the order of objects. For example, consumers buy different wines consistent with the country of origin of the music (Germany vs. France) currently playing in a store, or choose more often food products that are placed in the center than at both extremes (North, Hargreaves, \& McKendrick, 1999; Valenzuela \& Raghubir, 2009). In a similar vein, many decisions are not made based on lengthy deliberate thinking, but on quick and automatic heuristic processing (Kahneman, 2012). Indeed, most of the time, people do not have the time, motivation, or cognitive resources to carefully and consciously think through all the decisions they make throughout the day. For example, research has shown that more than 200 daily food-related decisions are made outside of conscious awareness, and that habits and impulses govern many decisions (Chartrand, 2005; Hofmann et al., 2009; Marteau, Hollands, \& Fletcher, 2012; Salmon, Fennis, De Ridder, Adriaanse, \& De Vet, 2014; Verhoeven, Adriaanse, Evers, \& De Ridder, 2012; Wansink \& Sobal, 2007).

Currently, dual process theories have a prominent role in explaining behavioral decision-making. These theories specify two different types of thinking processes that govern our behaviors: A slow, effortful, rule-based, deliberate, and conscious thought process and a fast, effortless, automatic, affective, and nonconscious thought process (see Hofmann et al., 2009; Kahneman, 2012; Marteau et al., 2012; Osman, 2004; Sheeran, Gollwitzer, \& Bargh, 2013; Sloman, 1996). The latter process is typically responsible for most of our behaviors and decisions, in contrast to older behavioral models claiming that behaviors and decisions are mainly conscious and deliberate. For example, decisions are often based on popularity, emotion, attention, or familiarity, rather than a rational cost-benefit analysis. After the advent of Thaler and Sunstein's book in 2008 called "Nudge: Improving Decisions about Health, Wealth, and Happiness", interventions based on these insights were grouped under the umbrella term of "nudging". Other names are being used to define these interventions, such as choice architecture, but ultimately nudging has become the most popular label for describing this type of intervention. Many of the studies in psychology could thus retrospectively be categorized as having examined nudges. For example, the default nudge was already used by some countries who had an opt-out (vs. opt-in) strategy to increase organ donation (Johnson \& Goldstein, 2003), and nudges have been 
previously used to steer patients' choices for a certain operation or therapy (McNeil, Pauker, Sox, \& Tversky, 1982; O'Connor, 1988). Nudging elaborates thus on previously existing knowledge about automatic psychological processes and related phenomena. As such, nudging is not a new research field, but a clever application of knowledge on behavior change and decision-making, that is now finding its way into policy making and consumer welfare. The main difference between nudging and other interventions such as education campaigns is that nudging does not compete with our most used way of thinking but respects it because it does not attempt to engender behavioral change through conscious processes.

Most of the time, people do not have the time, motivation, or resources to think consciously, rationally, and logically. As a result, most behaviors are part of habits, heuristic processes, unconscious associations, or automatic and learned responses, rather than logical and rational processes (Hofmann et al., 2009; Kahneman, 2012; Smith \& DeCoster, 2000). Nudges then take advantage of the unconscious interaction between a person and the environment, and thus of the so-called System 1 way of thinking, making use of flaws that affect automatic unconscious processes and passive decision-making, such as the fact that people do not give full attention to their options, they tend to follow the path of "least resistance", they lack clear preferences and complete information, and choices will inevitably be influenced by default rules, frames, and starting points (Sunstein \& Thaler, 2003; Thaler \& Sunstein, 2008).

\section{2 | Definitions and categorizations of nudging}

Several definitions of nudges have been suggested so far, with most of them converging towards the same conceptualization as the original definition by Thaler and Sunstein: "A nudge, as we will use the term, is any aspect of the choice architecture that alters people's behavior in a predictable way without forbidding any options or significantly changing their economic incentives. To count as a mere nudge, the intervention must be easy and cheap to avoid. Nudges are not mandates. Putting the fruit at eye level counts as a nudge. Banning junk food does not." (Thaler \& Sunstein, 2008, p. 6). Most researchers agree with the original definition, but take care to stress out a bit more certain aspects of nudging. Hausman and Welch, for example, insist on how, besides making alternatives more costly financially or economically, no additional cost in terms of time, trouble, or social sanctions should be added (Hausman \& Welch, 2010). They also stress out the central role of cognitive biases in human decision-making, and how nudges prey on these biases or flaws. Finally, Hansen and Jespersen describe how nudges are part of an attempt to intentionally and predictably influence choices and behaviors (Hansen \& Jespersen, 2013).

Considering these suggestions for specification of the original definition, we propose the following as a tentative and comprehensive working definition of nudging, which includes the core elements agreed upon by authors: Nudging is an umbrella term for deliberate and predictable methods of changing people's behavior by modifying the cues in the physical and/or social context in which they act. It uses these cues to activate nonconscious thought processes involved in human decision-making. Nudging implies that none of the choices should be difficult to avoid, made mandatory, incentivized economically or socially, and made significantly more costly in terms of time or trouble.

Similar to the definition of nudging, several authors have also discussed strategies for identifying ways to coherently categorize the many types of nudging interventions. For example, Thaler and Sunstein suggested that nudges can be divided in four types, namely changing standard options, changing the physical environment, providing the possibility to correct impulsive choices, and providing feedback on choices. Hansen and Jespersen proposed that nudges could fit into four categories based on whether they are unconscious or conscious, and transparent or nontransparent (Hansen \& Jespersen, 2013). Marteau and colleagues suggested three types of nudges, specifically nudges that alter the properties of the stimulus, that alter the placement of the stimulus, and that accompany the stimulus (Hollands et al., 2013). Another group of researchers suggested four descriptive dimensions as an organizational framework for nudges, such as whether nudges are boosting self-control or activating a desired behavior, externally-imposed or self-imposed, mindful or mindless, and encouraging or discouraging a behavior (House, Lyons, \& Soman, 2013). Finally, the British Behavioral Insights Team suggested no less than nine different types of nudges 
and cognitive heuristics nudges tap into, abbreviated in the acronym MINDSPACE, comprising messenger, incentives, norms, defaults, salience, priming, affect, commitment, and ego (Dolan, Hallsworth, Halpern, King, \& Vlaev, 2010).

Indeed, similar to the definition of nudging, authors are still discussing the best way to categorize nudging interventions. Some of these discussions highlight again the need for further research in order to get a clear and comprehensive understanding of the nudging concept and derive a complete definition and categorization of nudging.

\section{3 | Contemporary nudging}

Nudging refers to behavioral change strategies with huge potential. It has been successfully applied to several domains, and has been acclaimed by the public and private areas as the new panacea to solve societal issues. These successes have, however, obscured the fact that research in nudging is still ongoing, and that more research is needed to fine tune this tool before being put in the market and being widely applied by policy makers. In fact, the popularity of nudging may have contributed to some debates being raised before having a complete understanding of the concept, such as the use and public approval of nudges, which may harm this promising tool to change behavior (Bovens, 2009; De Ridder, 2014; Marteau et al., 2012; Yeung, 2012). We posit that the debate on nudges is due to the lack of more in-depth research and knowledge surrounding several unanswered questions in nudging, which in part arose from its new application in fields such as policy making and consumer welfare. In other words, these legal, political, scientific and economic debates stem from the scarce work and insights into pressing issues surrounding the application of well-established psychological knowledge in policy making, such as how nudges affect autonomous decision-making and long-term effects and transparency of nudging. We posit that these new applications of behavioral insights call for thorough psychological investigation.

A striking example of the need to move to the next level of research in nudging comes from the US. In 2012, New York mayor Michael Bloomberg proposed to ban the sale of sodas and other sugary drinks larger than 16-ounces $(47 \mathrm{cl})$ in restaurants, movie theaters, and food carts. This ban, labeled "the Big Gulp ban", aimed at reducing obesity and promoting healthier behavior. Faced with serious criticism, Bloomberg explained that this ban was more a sort of nudge than an actual ban. Richard Thaler promptly distanced himself from this affirmation, as did other researchers and politicians, as in his view the Bloomberg action still qualified as a ban and did not support the assumptions made by nudges, as envisioned by himself and Cass Sunstein, the founding fathers of the nudge concept (Thaler \& Sunstein, 2008). By contrast, for other researchers, such as Hansen (http://inudgeyou.com/the-big-gulp-ban-a-nudge-or-not/), the Big Gulp ban does qualify as a nudge, similar to interventions aimed at reducing food portion sizes or at replacing large plates with smaller ones, reasoning that the Bloomberg intervention does not impede consumers to drink more than 16-ounces of sodas, as they could go for a refill or buy a second drink. This debate shows how researchers and policy makers widely discuss the basic elements of the nudging concept (Bonell, McKee, Fletcher, Wilkinson, \& Haines, 2011; Hansen \& Jespersen, 2013; Hausman \& Welch, 2010; Sugden, 2009). While cost may be perceived differently depending on the nudging intervention, the Big Gulp ban example shows how it is still unclear whether and what amount of additional effort (e.g., to get a refill) counts as "preserving freedom of choice", which is an essential part of the definition of nudging.

This paper aims to contribute an overview of the yet unresolved questions in nudging and to provide suggestions on how putting the focus back to the psychology may help to foster research to answer these questions. These findings should help to clearly define, categorize, and design nudging interventions; provide a coherent common ground for researchers and for policy makers; and potentially increase success rates of nudging interventions. Next, we will showcase four main questions in nudging that we think require further investigation to advance our understanding of this promising intervention tool. Of course, this list is not an exhaustive one, and other important issues could be mentioned, such as the situations where nudging trumps other interventions. We decided to focus on four issues because they pertain to the core underlying mechanisms of nudging, to how they work and under which conditions. Moreover, we recognized that past and future research in psychology could help shed light on these issues. This paper thus aims to highlight outstanding questions in the debate about nudging and to provide insights 
on how further research in psychology could help answer them. Hence, it does not aim to provide a definite answer to these questions. The four issues that we address are: The role of transparency, the definition of the choice set, the consequences of nudging, and freedom of choice. We believe that they are the most pressing questions in nudging research and that they are prototypical illustrations of how psychology could help to advance nudging.

\subsection{How effective are transparent nudging interventions?}

Nudges are subtle rearrangements of the choice architecture. This subtlety has raised some concerns as nudging may then not be ethical and manipulate people in a direction they may not be aware of. The House of Lords (2011) in Britain cited two criteria that should be met in order to consider a nudging intervention to be ethically acceptable. Choice architects should either tell people about an intervention directly, or ensure that a perceptive person can discern that an intervention had been implemented. Some authors have argued that disclosing the intervention may actually decrease the effectiveness of the nudge (Bovens, 2009). However, the claim that nudges are more effective precisely because they influence behavior more or less outside of conscious awareness has not been extensively and systematically tested. This shows again how nudging runs the risk of getting disconnected from its psychological roots and why it is important to put the psychology back. We state that psychological research is urgently needed to examine to what extent a nudging intervention can be disclosed or brought to conscious awareness while maintaining its effectiveness. Below, we suggest how research on automatic processes could be used to systematically examine the moderating role of transparency in nudging.

Psychological research has suggested that in case of automatic behaviors, people can be unaware of at least three parts of an intervention: The (physical) cue that triggers the behavior, the automatic process that is involved (i.e., the influence of the cue on the behavior), and the outcome behavior (Chartrand, 2005). Applied to nudging interventions, we could consider to disclose the nudge itself (e.g., a social proof statement revealing consumers' preferences), the automatic process (e.g., the need to belong to a group), and the outcome behavior (e.g., eat healthy food). An additional, fourth, element can be disclosed in nudging interventions, namely the source of the nudge (e.g., the supermarket manager). For (nudging) interventions, which make use of automatic processes to steer decisions, individuals are typically not aware of the process itself. However, they may or may not be aware of the other three elements of the nudging intervention.

Research in psychology has provided some clues on how making people aware of the process by which nudges influence behavior may impact on the effectiveness of the intervention. Conditioning literature tells us that individuals may sometimes respond more positively to conditioning when they are made aware of the pairing of the stimuli (Gorn, Jacobs, \& Mana, 1987). This may suggest that making individuals aware of the link between a cue and a behavior could lead to the nudging intervention being more effective or at least more accepted. However, measuring awareness by itself may sometimes not be sufficient to understand the effects of transparent nudging interventions. Research in communication has shown that the belief to be manipulated may be as important as just being aware of it. Studies have shown that people believe that they themselves cannot be influenced by trivial cues in the environment in contrast to other people, a phenomenon called the third person effect (Perloff, 1993). Individuals typically assume that mass communications exert a stronger impact on others than on themselves, and that their own decisions are made on a rational voluntary basis. Investigating the disclosure of nudging interventions as well as their reception by individuals may inform us on the effectiveness of transparent nudging interventions.

More recent research investigated directly how disclosing a specific aspect of a nudging intervention could impact its effectiveness. In this study, researchers disclosed the intended outcome of the intervention with a sign placed prominently on the counter stating "we are helping you to make healthy choices" (Kroese et al., 2015). They observed that this sign did not impact the effectiveness of a repositioning nudge aimed to increase healthy food choices. These results may be explained by the fact that most people usually agree on the importance and benefits of a healthy diet, and may actually welcome such interventions and even be willing to "fall" for them. Although these results are promising, it is yet unclear whether customers noticed the sign, and if they did, whether they believed that it could 
influence their choices, as we have seen with the third person effect. Indeed, when the purpose of the nudge was disclosed to customers in a follow-up interview, they were adamant to believe that it had no influence on their food choices. Yet sales of healthy food nearly doubled over the week-long intervention. This finding is corroborated by a study on nudging approval that demonstrated that people did not think that they would be influenced by nudges, but believed that other people would (Junghans, Cheung, \& De Ridder, 2015).

Another recent study aimed to make individuals aware of the nudge itself (Loewenstein, Bryce, Hagmann, \& Rajpal, 2015). Participants were asked to choose a hypothetical advance directive in case of medical illness. One of the directives was nudged by making it the default choice. Participants were then told about the default selection, and that they were able to change it afterward. Results showed that warning participants that they were being nudged did not moderate the effects of this nudge. This study provides further support that disclosing aspects of a nudging intervention may not render it ineffective, at least not when nudging health-related behaviors. This finding is supported by recent studies from the same researchers, who showed that when making advance directives or choosing whether to have green amenities in their new flat, people are not influenced by knowing in advance that they are being nudged or that one option is a default. Another study found that nudge awareness may actually even become beneficial, as disclosing, the nudge may alert people to the dangers of choosing blindly and prompt them to take informed decisions (Isoni et al., forthcoming). These studies provide initial evidence on the effects of disclosing a specific aspect of a nudge, yet further investigation is necessary to ascertain that transparent nudges may not lose out on effectiveness.

The effects of disclosing the source of a nudge can only be inferred. Research on heuristics has shown that the approval and compliance with messages or instructions are highly dependent on the source of the message (Cialdini, 2009). Evaluations of the source such as liking, authority or social acceptance are significant moderators of the effects of a source on an individual's behaviors. For example, messages conveyed by an authority figure such as a doctor, or a very well-liked figure, such as a famous actor, are typically more accepted and followed upon by individuals. In a recent survey, researchers observed that the source did impact approval of nudging, such that nudges designed by experts were more welcomed than nudges designed by the industry or policy makers (Junghans, Marchiori, Cremers, Evers, \& De Ridder, forthcoming). Moreover, the trustworthiness of the source mediated this effect, such that the more a source was trusted, the more the nudge was approved of. This survey shows that disclosing the source of a nudge may impact its effectiveness, but that this relationship may be dependent on the trustworthiness and authority of the source itself. The moderating role of the source has been further supported in a recent study by Tannenbaum and colleagues, who showed that people agree or oppose nudges depending on whether the source proposing the nudge matches their political orientation (Tannenbaum, Fox, \& Rogers, Under review).

In sum, evidence seems to show that making individuals aware of a nudging intervention may not affect its effectiveness, although more systematic research, as suggested here, is needed to confirm these findings. Nudges are often criticized for violating autonomy because of their covert nature, yet this subtlety may actually not be necessary for nudging interventions to be effective.

\subsection{How should the choice set of a nudging intervention be determined?}

A second question which we believe warrants further investigation in nudging is how broad (or small) the choice set should be. Nudges typically aim to steer an individual toward a specific option, and away from alternative options. Can nudges meddle with the number of options available, and thus choices? A first clarification that is needed is that currently the two concepts of options and choices are used interchangeably. In the Big Gulp ban example, we saw that forbidding options, such as the ban on 16-ounces cups, does not count as a nudge according to some nudge researchers. Yet forbidding this option does not forbid the choice to take a refill or buy a second cup. While this rationale holds up for customers deciding to dine in, such an intervention could not be labeled a nudge if customers decide to leave after their purchase. Indeed, nudges that successfully decreased food consumption and food waste 
have used reduced tableware sizes (Thaler \& Sunstein, 2008). This example shows how it is still unclear to what extent interventions that modify a choice set count as nudges. It is thus important to disentangle choices from options, and to determine rules that have to be taken into account when deciding upon the choice architecture of a nudging intervention. From a psychological perspective, an additional step in nudging research is thus to examine how modifying a choice set impacts an individuals' decision-making capacity and experience. Importantly, while this consideration may apply to most nudging interventions (e.g., defaults, social norms, and rearrangements), there are some cases where this caution may be unnecessary. Our arguments below thus mainly apply to these former intervention types.

When deciding to modify a choice set, we believe that choice architects should be able to forbid an option, such as 16-ounces cups, but should not be able to forbid a choice, such as to drink more, refuse a refill or the sale of a second drink. Clearly, an intervention banning an option that would result in inhibiting a choice cannot be labeled a nudge. This distinction is crucial, as research in psychology has shown that the number of options that are made available has important consequences on behavior and decision experience. Indeed, reducing choice sets does not only nudge people into making different choices, but can also help to decrease the complexity of making choices, reduce the likelihood of opting out of making a decision, and lessen anxiety to choose, a phenomenon called choice overload (Scheibehenne, Greifeneder, \& Todd, 2010; Schwartz, 2004). This literature demonstrated that decreasing the number of options can significantly lead to more satisfying choices. In this view, reducing the number of options, while keeping the choices intact, may actually be beneficial for the nudgee. No research so far investigated whether and how choice overload can affect nudging interventions. Based on the choice overload literature, we would predict that reducing the set of options, while keeping all choices available, can facilitate decision-making outcome and experience, and thus contribute to designing better nudges.

A second point to consider when determining the choice set of a nudging intervention is how the preferred and the alternative options will be perceived by individuals. A nudging intervention can either increase the value of an option (e.g., choose an apple) or decrease the value of the alternative option (e.g., choose a chocolate chip cookie). In other words, preferred options can be made more popular, salient, or visible, or non-preferred options can be made less popular, salient, or visible. In practice, this distinction may sometimes not be so apparent, as valorizing one option usually automatically de-valorizes its alternatives in consumers' minds, also called the devaluation effect (Brendl, Markman, \& Messner, 2003). Research has shown, however, that valorized behaviors increase the evaluation and the motivation to pursue the specific behavior (Elliot, 2006) and should therefore be preferred over de-valorizing less preferred options. Moreover, valorized goals contribute positively to creativity, social interaction satisfaction, intrinsic motivation, and importantly, product evaluation (Friedman \& Forster, 2002; Srachman \& Gable, 2006). Future research needs to examine whether nudging interventions that frame preferred options in valorized terms also similarly lead to people having more positive attitudes toward that option. Previous research would suggest that individuals may ultimately increase their intrinsic motivation to continue performing the nudged behavior and/or develop positive attitudes towards it (Elliot \& Covington, 2001), which would be in line with the main objective of nudging theory.

\subsection{What are the consequences of nudging?}

Nudging interventions are often portrayed as one-shot localized interventions. For example, a customer enters a restaurant and is nudged into choosing the healthy side-dish after making it the default. Nudging theory typically examined the effectiveness of a nudge within a specific situation, and it is unclear as to whether these effects might spill over to other choices and/or situations. While nudging interventions have been shown to have the potential to modify behavior in a specific decision-making situation, we argue that a next step in nudging research is to focus on examining long-term effects of nudging. No research so far has investigated consequences of nudging interventions from a psychological perspective, such as spill-over effects of interventions to different choices, different locations, or different times. Currently, there is mixed evidence on the long-term effects of nudging (see 
Dupas, 2012; Giné, Karlan, \& Zinman, 2010; Gneezy, Meier, \& Rey-Biel, 2011), which supports our claim for further systematic research. This inconsistency in results may be partly due though to the heterogeneity of nudging interventions and future research should examine to what extent these differences impact our understanding of long-term effects of nudges. Below, we focused on more general consequences of nudging interventions that are less dependent on the specific type of intervention, but we advise to take this heterogeneity into account. This research is needed to implement effective long-lasting interventions that actually help people reach their goals over longer periods of time. It is therefore still an open question whether it is advised to suggest nudging to policy makers as a long-term effective intervention tool.

In order to answer these questions, different lines of research could be taken account, which yield different - if not opposing - potential long-term effects. Research on self-licensing has shown that a good behavior is sometimes "compensated" by a bad behavior. Individuals choosing a healthy treat (because of a nudge) may use this choice as a justification or license to indulge in unhealthy treats later (De Witt Huberts, Evers, \& De Ridder, 2014). For example, completing a complicated work task might be used as a justification (or license) to skip an evening language class. A study showed that individuals who were made to believe that they exerted a huge effort compensated this with increased consumption of junk food (De Witt Huberts, Evers, \& De Ridder, 2012). Hence, the self-licensing literature would predict that a nudging intervention may not yield positive long-term effects, with individuals eventually using the nudged choice as an excuse to indulge.

By contrast, other psychological research suggests that a nudge could spill over to a different situation or choice. For example, when someone is nudged into performing a behavior that is novel for him/her, this may create surprise at first. Cognitive dissonance theory (Festinger, 1957) explains that such a person may experience some discomfort that will be resolved either by considering the behavior as an exception or by rationalizing that he/she is actually a person performing such behaviors. The latter strategy may then lead to the person conforming to the nudge again in a different situation, or picking the same option in a nudge-free situation. Research has shown that individuals' evaluation of (nudged) choices can lead to attitude reinforcements through self-perception processes and simple action-to-attitude inferences (Bem, 1967, 1972). Hence, this research would - contrary to the work on self-licensing - suggest that nudging someone may have positive long-term effects, with an individual probably embracing the nudged behavior as part of their identity.

In the same vein, research on automatic behaviors has shown that individuals are creatures of habits. Habits are formed when a behavior is performed in response to a cue and is repeated enough times to become automatically triggered in a certain context (Verplanken \& Aarts, 1999). Hence, merely encountering such a context is sufficient to activate mental representations of habitual actions allowing for automatic execution of behavior. For example, a traveler at the station has a habit to buy a croissant every morning: The mere sight of the shop automatically triggers a mindless behavior to reach for the delicious treat, and before even realizing it, our traveler is munching on their croissant. A nudge that would be paired with a specific cue may then later on develop as a habit, where the behavior is triggered by the mere presence of the cue, even after the nudge has been removed. These insights in human decision-making would thus suggest that a paired nudge-cue could produce positive long-term effects even when the nudge has been removed.

In sum, it is unclear whether a nudge can influence behavior and choice beyond the specific occasion where the nudge was presented. Future research should examine whether nudges are vulnerable to a boomerang or licensing effect, or whether they can help to empower people into creating new habits that will last even when the intervention is removed. Knowing how people react to (multiple) nudging can potentially inform public debates on the ethics and applicability of nudging.

\section{7 | How should we conceptualize "freedom of choice" in a nudging intervention?}

Freedom of choice is one of the key principles in nudging interventions and has been discussed extensively (Bovens, 2009; Hansen \& Jespersen, 2013; Sunstein, 2014; Wilkinson, 2013). People are steered toward a specific choice, but 
should always be able to choose any other option they want, without coercion. Consequently, certain boundary conditions have been identified to ascertain freedom of choice. These conditions were operationalized by stressing that the alternative, non-nudged, option should not be made significantly more costly in terms of money, time, trouble, or social sanctions (Hansen \& Jespersen, 2013; Hausman \& Welch, 2010; Thaler \& Sunstein, 2008). For example, raising the price of unhealthy food with a fat-tax clearly does not preserve freedom of choice, at least not for those with limited funds. Next to these measurable requirements to objective freedom of choice, people may experience other, less tangible, factors that could limit their perception of freedom of choice, which underlie the psychological mechanisms of nudging.

This obstacle to perceived freedom of choice may be less of a problem when the nudged behavior aligns with someone's goals. For example, painting foot steps leading to the stairs instead of the elevator has been shown to increase stair usage (Zimmerman, 2009). Someone aiming to exercise more often may appreciate such a nudge, whether they are aware of it or not. By contrast, someone aiming to enjoy the nice elevator music may become angry once the covert manipulation is noticed. Psychology has theorized extensively on the impact of goals on behaviors, such as goal conflicts, goal hierarchy, or the interplay between short- and long-term goals. Goals are typically defined as mental representations of desired states (Emmons, 1999). Much behavior is thought to be goal-directed, and as such they can influence the onset, the maintenance, and the stoppage of behaviors. Nudging interventions should help people to make better decisions that align with their goals. Hence, interventions that help people reach their goals should count as freedom preserving nudges. Interventions that work independent of people's goals would by contrast be less freedom preserving.

While it is important to take into account the type of goals that people hold, perceived freedom of choice in nudging interventions can also be impaired by conflicting goals. Indeed, another research area in the domain of goaldirected behavior is the amount of conflict that people experience between the current choice and future goals. This conflict can arise when short- and long-term goals differ, such as aiming for immediate pleasure and indulge in a chocolate cake or aim for delayed gratification such as good health and decide to go for a run instead. A goal conflict can also arise between similar temporal goals, such as deciding to work on a personal project or help out a friend. A wealth of research has been conducted on the effects of goal conflicts and hierarchy on behaviors (see Stroebe, Van Koningsbruggen, Papies, \& Aarts, 2013). Nudges help people resolve such conflicts by steering them toward one of the options, and could endanger their perception of choice freedom when the nudged behavior is not the intended goal of the nudgee.

The decision on whether to use nudges targeting System 1 or System 2 thought processes to uphold the perception of freedom of choice is also dependent on people's evaluation and approval of these interventions. Recent studies have shown that people typically prefer interventions that are more obvious and that engage their deliberate thinking (i.e., System 2), especially in important contexts (Jung \& Mellers, 2016; Sunstein, 2016a). They want to feel in control of these more important decisions and not rely on fast impulsive processes. However, once participants are explained the differences, and how System 1 nudges can be more effective than System 2 nudges to change their behavior, people do not hesitate to switch their approval (Sunstein, 2016a). As illustrated previously, there are other factors that influence individuals' approval of nudging techniques, such as whether the behavior targeted aligns with a person's goals, individual dispositions and/or political orientation, although the latter may depend on whether people live in Europe or USA (Jung \& Mellers, 2016; Reisch \& Sunstein, 2016; Sunstein, 2016b). These factors may also contribute to people's perception of whether nudges infringe on freedom of choice.

Determining whether nudges are freedom preserving should thus also take into account the working mechanisms of nudges and how goals can be used as a measure of freedom of choice. An important question and addition to the current freedom preserving criteria is thus to understand how to operationalize perceived freedom of choice when people choose automatically. Answering this question will help to define freedom of choice more clearly, without confusing rationality, freedom, and consciousness. 


\section{I CONCLUSION}

The popularity of nudges as a tool to change people's behaviors has taken worldwide proportions (Whitehead et al., 2014). Nudging interventions are easy to implement, effective, and nearly cost free. While initial research has shown promising results, several questions are still unresolved. Most research so far focused on the legal and economic moderators of a nudging intervention, neglecting important psychological factors. This paper highlights several questions that have received little attention so far from nudging researchers. Answers to these questions, derived from psychological research, may help to advance nudging theory and implementation. A first issue that needs further attention concerns the effects of disclosing a nudging intervention, such that individuals may become aware of the influence that several aspects of the choice architecture could have on their behavior. It is unclear yet to what extent nudging interventions can be disclosed without losing effectiveness and whether individuals' belief of being influenced can moderate this effect. Secondly, rules are necessary to determine the way to present choice options. Taking into account how the choice set can impact decision-making and experience is of utmost importance in order to maximize the effects of nudging interventions. A third under-investigated question relates to the consequences of a nudging intervention, and how subsequent behavior is performed, whether it was nudged or not. Finally, identifying and examining psychological criteria next to the current rational ones will help to ensure freedom of choice. These questions aim to inspire further research in nudging to complement the already comprehensive knowledge we have about this promising tool of behavior change and to help to develop more specific insights regarding nudging theory and the implementation of nudges.

\section{ACKNOWLEDGEMENTS}

This research was financially supported by the Netherlands Organization for Scientific Research (NWO) in the framework of project (FCBG 057-13-001), which was supplemented by financial contributions from Unilever R\&D Vlaardingen, The Netherlands, and FrieslandCampina, Amersfoort, The Netherlands.

\section{REFERENCES}

Bargh, J. A., \& Chartrand, T. L. (1999). The unbearable automaticity of being. American Psychologist, 54, 462-479. doi:10.1037/0003-066X.54.7.462

Bem, D. J. (1972). Self-perception theory. In L. Berkowitz (Ed.), Advances in experimental social psychology (pp. 1-62). New York: Academic Press.

Bem, D. J. (1967). Self-perception: An alternative interpretation of cognitive dissonance phenomena. Psychological Review, 74, 183-200. doi:10.1037/h0024835

Blumenthal-Barby, J. S., \& Burroughs, H. (2012). Seeking better health care outcomes: The ethics of using the "Nudge". The American Journal of Bioethics, 12, 1-10. doi:10.1080/15265161.2011.634481

Bonell, C., McKee, M., Fletcher, A., Wilkinson, P., \& Haines, A. (2011). One nudge forward, two steps back. British Medical Journal, 342, d401. doi:10.1136/bmj.d401

Bovens, L. (2009). The ethics of nudge. In T. Grüne-Yanoff, \& S. O. Hansson (Eds.), Preference change: Approaches from philosophy, economics and psychology (pp. 207-219). Berlin: Springer.

Brendl, C. M., Markman, A. B., \& Messner, C. (2003). The devaluation effect: Activating a need devalues unrelated choice options. Journal of Consumer Research, 29, 463-473. doi:10.1086/346243

Chartrand, T. L. (2005). The role of conscious awareness in consumer behavior. Journal of Consumer Psychology, 15, 203-210. doi:10.1207/s15327663jcp1503_4

Cialdini, R. (2009). Influence: Science and practice. Boston, MA: Pearson Education.

De Ridder, D. T. D. (2014). Nudging for beginngers: A shortlist of issues in urgent need of research. The European Health Psychologist, 16, 2-6. doi:10.1874/307764

De Witt Huberts, J. C., Evers, C., \& De Ridder, D. T. D. (2012). License to sin: Self-licensing as underlying mechanism of hedonic consumption. European Journal of Social Psychology, 42, 490-496. doi:10.1002/ejsp.861 
De Witt Huberts, J. C., Evers, C., \& De Ridder, D. T. D. (2014). Because I am worth it: A theoretical framework and empirical review of a justification-based account of self-regulation failure. Personality and Social Psychology Review, 18, 119-138. doi:10.1177/1088868313507533

Dolan, P., Hallsworth, M., Halpern, D., King, D., \& Vlaev I. (2010). Mindspace: Influencing behaviour through public policy. Institute For Government. http://www.instituteforgovernment.org.uk/publications/mindspace.

Dupas, P. (2012). Health behavior in developing countries. Annual Review of Economics, 3, 1-39.

Elliot, A. J., \& Covington, M. V. (2001). Approach and avoidance motivation. Educational Psychology Review, 13, 73-92. doi:10.1023/A:1009009018235

Elliot, A. (2006). The hierarchical model of approach-avoidance motivation. Motivation and Emotion, 30, 111-116. doi:10.1007/s11031-006-9028-7

Emmons, R. A. (1999). The psychology of ultimate concerns: Motivation and spirituality in personality. New York: Guilford Press.

Festinger, L. (1957). A theory of cognitive dissonance. Stanford, CA: Stanford University Press.

Friedman, R. S., \& Forster, J. (2002). The influence of approach and avoidance motor actions on creative cognition. Journal of Experimental Social Psychology, 38, 41-55. doi:10.1006/jesp.2001.1488

Giné, X., Karlan, D., \& Zinman, J. (2010). Put your money where your butt is: A commitment contract for smoking cessation. American Economic Journal: Applied Economics, 2, 213-235. doi:10.1257/app.2.4.213

Gneezy, U., Meier, S., \& Rey-Biel, P. (2011). When and why incentives (don't) work to modify behavior. The Journal of Economic Perspectives, 25, 91-209.

Gorn, G. J., Jacobs, W. J., \& Mana, M. J. (1987). Observations on awareness and conditioning. In M. Wallendorf, \& P. Anderson (Eds.), Advances in consumer research (pp. 415-416). Provo, UT: Association for Consumer Research.

Hansen, P. G., \& Jespersen, A. M. (2013). Nudge and the manipulation of choice: A framework for the responsible use of the nudge approach to behaviour change in public policy. The European Journal of Risk Regulation, 4, 3-28. Available at SSRN: http://ssrn.com/abstract=2555337

Hausman, D. M., \& Welch, B. (2010). Debate: To nudge or not to nudge. Journal of Political Philosophy, 18, $123-136$. doi:10.1111/j.1467-9760.2009.00351.x

Hofmann, W., Friese, M., \& Strack, F. (2009). Impulse and self-control from a dual-systems perspective. Perspectives on Psychological Science, 4, 162-176.

Hollands, G. J., Shemilt, I., Marteau, T. M., Jebb, S. A., Kelly, M. P., Nakamura, R., ... Ogilvie, D. (2013). Altering micro-environments to change population health behavior: Towards an evidence base for choice architecture interventions. British Medical Journal: Public Health, 13, 1218. doi:10.1186/1471-2458-13-1218

House, J., Lyons, E., \& Soman, D. (2013). Towards a taxonomy of nudging strategies. Research Report Series: University of Toronto.

Johnson, E. J., \& Goldstein, D. G. (2003). Do defaults save lives. Science, 302, 1338-1339. Available at SSRN: http://ssrn.com/ abstract $=1324774$

Jung, J. Y., \& Mellers, B. A. (2016). American attitudes toward nudges. Judgment and Decision making, 11, $62-74$.

Junghans, A. F., Cheung, T. L., \& De Ridder, D. T. D. (2015). Under consumer's scrutiny - An investigation into consumers attitudes and concerns about nudging in the realm of health behaviir. BMC Public Health, 15, 336.

Junghans, A.F., Marchiori, D.R., Cremers, J., Evers, C., \& De Ridder, D.T.D. (forthcoming). The who and how of nudging crossnational perspectives on consumer approval in eating behavioral.

Kahneman, D. (2012). Thinking, fast and slow. New York: Farrar, Strauss \& Giroux.

Kroese, F. M., Marchiori, D. R., \& De Ridder, D. T. D. (2015). Nudging healthy food choices: A field experiment at the train station. Journal of Public Health, 1-5. doi:10.1093/pubmed/fdv096

Loewenstein, G., Bryce, C., Hagmann, D., \& Rajpal, S. (2015). Warning: You are about to be nudged. Behavioral Science \& Policy, 1, 35-42.

Marteau, T. M., Hollands, G. J., \& Fletcher, P. C. (2012). Changing human behavior to prevent disease: The importance of targeting automatic processes. Science, 337, 1492-1495. doi:10.1126/science.1226918

McNeil, B. J., Pauker, S. G., Sox, H. C. Jr., \& Tversky, A. (1982). On the elicitation of preferences for alternative therapies. The New England Journal of Medicine, 306, 1259-1262. doi:10.1056/NEJM198205273062103

North, A. C., Hargreaves, D. J., \& McKendrick, J. (1999). The influence of in-store music on wine selections. Journal of Applied Psychology, 84, 271-276.

O'Connor, A. M. (1988). Effects of framing and level of probability on patients' preferences for cancer chemotherapy. Journal of Clinical Epidemiology, 42, 119-126. doi:10.1016/0895-4356(89)90085-1 
Osman, M. (2004). An evaluation of dual-process theories of reasoning. Psychonomic Bulletin \& Review, 11, 988-1010. doi:10.3758/BF03196730

Perloff, R. M. (1993). Third-person effect research 1983-1992: A review and synthesis. International Journal of Public Opinion Research, 5, 167-184. doi:10.1093/ijpor/5.2.167

Prinsen, S., De Ridder, D. T. D., \& De Vet, E. (2013). Eating by example: Effects of environmental cues on dietary decisions. Appetite, 70, 1-5. doi:10.1016/j.appet.2013.05.023

Reisch, L. A. \& Sunstein, C. R., Do europeans like nudges? (February 27, 2016). Judgment and Decision Making, Forthcoming. Available at SSRN: http://ssrn.com/abstract=2739118 or https://doi.org/10.2139/ssrn.2739118

Salmon, S., Fennis, B. M., De Ridder, D. T. D., Adriaanse, M. A., \& De Vet, E. (2014). Health on impulse: When low self-control promotes healthy food choices. Health Psychology, 33, 103-109. https://doi.org/10.1037/a0031785

Scheibehenne, B., Greifeneder, R., \& Todd, P. M. (2010). Can there ever be too many options? A meta-analytic review of choice overload. Journal of Consumer Research, 37, 409-425. doi:10.1086/651235

Schwartz, B. (2004). Paradox of choice. New York: Harper Perennial.

Sheeran, P., Gollwitzer, P. M., \& Bargh, J. A. (2013). Non-conscious processes and health. Health Psychology, 32, 460-473. https://doi.org/10.1037/a0029203

Skov, L. R., Lourenço, S., Hansen, G. L., Mikkelsen, B. E., \& Schofield, C. (2013). Choice architecture as a means to change eating behaviour in self-service settings: A systematic review. Obesity Reviews, 14, 187-196. doi:10.1111/j.1467789X.2012.01054.x

Sloman, S. A. (1996). The empirical case for two systems of reasoning. Psychological Bulletin, 119, 3-22. https://doi.org/ 10.1037/0033-2909.119.1.3

Smith, E. R., \& DeCoster, J. (2000). Dual-process models in social and cognitive psychology: Conceptual integration and links to underlying memory systems. Personality and Social Psychology Review, 4, 108-131. doi:10.1207/ S15327957PSPR0402_01

Srachman, A., \& Gable, S. L. (2006). What you want (and do not want) affects what you see (and so not see): Avoidance social goals and social events. Personality and Social Psychology Bulletin, 32, 1446-1458. doi:10.1177/0146167206291007

Stroebe, W., Van Koningsbruggen, G. M., Papies, E. K., \& Aarts, H. (2013). Why most dieters fail but some succeed: A goal conflict model of eating behavior. Psychological Review, 130, 110-138. doi:10.1037/a0030849

Sugden, R. (2009). On nudging: A review of nudge: improving decisions about health, wealth and happiness by Richard $\mathrm{H}$. Thaler and Cass R. Sunstein. International Journal of the Economics of Business, 16, 365-373. doi:10.1080/ 13571510903227064

Sunstein, C. R., \& Thaler, R. H. (2003). Libertarian paternalism is not an oxymoron. The University of Chicago Law Review, 70 , 1159-1202. https://doi.org/10.2139/ssrn.405940

Sunstein, C. R. (2014). Why nudge. The Politics of Libertarian Paternalism: Yale University Press.

Sunstein, C. R. (2016a). People prefer System 2 nudges (Kind Of) (July 19, 2016). Duke Law Journal, 66. Available at SSRN: http://ssrn.com/abstract=2731868 or http://dx.doi.org/10.2139/ssrn.2731868

Sunstein, C. R. (2016b). Do people like nudges? (February 17, 2016). Administrative Law Review, Forthcoming. Available at SSRN: http://ssrn.com/abstract=2604084 or http://dx.doi.org/10.2139/ssrn.2604084.

Tannenbaum, D., Fox, C.R., \& Rogers, T. (Under review). Partisan nudge bias: How politics distort preferences for behavioral policy tools.

Thaler, R. H., \& Sunstein, C. R. (2008). Nudge: Improving decisions about health, wealth, and happiness. Yale University Press.

Valenzuela, A., \& Raghubir, P. (2009). Position-based beliefs: The center-stage effect. Journal of Consumer Psychology, 19, 185-196. doi:10.1016/j.jcps.2009.02.011

Van Kleef, E., Otten, K., \& van Trijp, H. (2012). Healthy snacks at the checkout counter: A lab and field study on the impact of shelf arrangement and assortment structure on consumer choices. British Medical Journal: Public Health, 12, $1072-1082$.

Verhoeven, A. A. C., Adriaanse, M. A., Evers, C., \& De Ridder, D. T. D. (2012). The power of habits: Unhealthy snacking behaviour is primarily predicted by habit strength. British Journal of Health Psychology, 17, 758-770. doi:10.1111/ j.2044-8287.2012.02070.x

Verplanken, B., \& Aarts, H. (1999). Habit, attitude, and planned behavior: Is habit an empty construct or an interesting case of goal-directed automaticity. In W. Stroebe, \& M. Hewstone (Eds.), European review of social psychology (Vol. 10) (pp. 101-134). Chichester, England: Wiley.

Wansink, B., \& Sobal, J. (2007). Mindless eating: The 200 daily food decisions we overlook. Environment and Behavior, 39, 106-123. doi:10.1177/0013916506295573 
Whitehead, M., Jones, R., Howell, R., Lilley, R., \& Pykett, J. (2014). Nudging all over the world: Assessing the global impact of the behavioural sciences on public policy. Economic and Social Research Council.

Wilkinson, P. (2013). Nudging and manipulation. Political Studies, 61, 341-355.

Yeung, K. (2012). Nudge as fudge. The Modern Law Review, 75, 122-148.

Zimmerman, F. J. (2009). Using behavioral economics to promote physical activity. Preventive Medicine, 49, $289-291$. doi:10.1016/j.ypmed.2009.07.008

How to cite this article: Marchiori, D., Adriaanse, M. A., and De Ridder, D. T. D. Unresolved questions in nudging research: Putting the psychology back in nudging, Soc Personal Psychol Compass 2017;11:e12297. doi: $10.1111 /$ spc3.12297.

\section{AUTHOR BIOGRAPHIES}

David R. Marchiori currently works as a post-doctoral researcher in the Department of Social, Health, and Organizational Psychology at Utrecht University, the Netherlands. He is interested in the interplay between the physical environment and health behaviors, such as food choices and exercise. More specifically, he examines how interventions such as nudging can help improving people's health and decision-making.

Marieke Adriaanse is an Associate Professor at the Department of Social Health and Organizational Psychology of Utrecht University. She has a broad interest in self-regulation and in the interplay of conscious and nonconscious processes on health behavior. Her two main research lines involve the use of planning strategies in the context of overriding unwanted habits and she investigates how people interpret and deal with behavior that is the product of nonconscious processes.

Denise de Ridder is professor of psychology at Utrecht University. She leads the Self-Regulation Lab within the Department of Social Health and Organizational Psychology. Her research is focused on understanding the interplay between reasoned and impulsive processes with a particular focus on the role of self-control. She is also concerned with translating the implications of these behavioral insights into policy making. 